
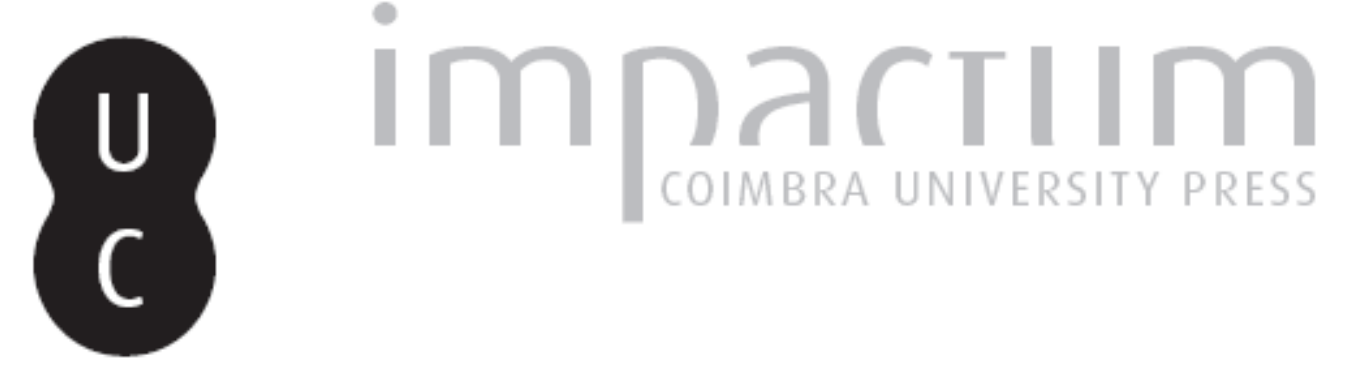

\title{
Uma etnografia sobre mulheres com cancro da mama: um estudo de caso no Instituto Português de Oncologia de Coimbra
}

\author{
Autor(es): $\quad$ Martins, Diana Isabel Silva \\ Publicado por: CIAS - Centro de Investigação em Antropologia e Saúde \\ URL \\ persistente: \\ URI:http://hdl.handle.net/10316.2/28573 \\ DOI: \\ DOI:http://dx.doi.org/10.14195/2182-7982_28_2 \\ Accessed : $\quad$ 26-Apr-2023 13:16:24
}

A navegação consulta e descarregamento dos títulos inseridos nas Bibliotecas Digitais UC Digitalis, UC Pombalina e UC Impactum, pressupõem a aceitação plena e sem reservas dos Termos e Condições de Uso destas Bibliotecas Digitais, disponíveis em https://digitalis.uc.pt/pt-pt/termos.

Conforme exposto nos referidos Termos e Condições de Uso, o descarregamento de títulos de acesso restrito requer uma licença válida de autorização devendo o utilizador aceder ao(s) documento(s) a partir de um endereço de IP da instituição detentora da supramencionada licença.

Ao utilizador é apenas permitido o descarregamento para uso pessoal, pelo que o emprego do(s) título(s) descarregado(s) para outro fim, designadamente comercial, carece de autorização do respetivo autor ou editor da obra.

Na medida em que todas as obras da UC Digitalis se encontram protegidas pelo Código do Direito de Autor e Direitos Conexos e demais legislação aplicável, toda a cópia, parcial ou total, deste documento, nos casos em que é legalmente admitida, deverá conter ou fazer-se acompanhar por este aviso.

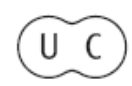




\section{Antropologia Portuguesa}

Departamento de Antropologia | Universidade de Coimbra

Volume $28 \cdot 2011$ 


\title{
Uma etnografia sobre mulheres com cancro da mama: um estudo de caso no Instituto Português de Oncologia de Coimbra
}

\author{
Diana Isabel Silva Martins \\ Departamento de Ciências da Vida \\ Universidade de Coimbra, Portugal \\ diana.martins@netcabo.pt
}

Resumo O cancro da mama é actualmente um grave problema de saúde pública, afectando uma em cada dez mulheres. Em Portugal, surgem aproximadamente 4500 novos casos por ano e cerca de 1500 são mortais. Esta doença tem uma enorme repercussão no espaço público, principalmente porque agride um órgão muito simbólico na maternidade e na feminilidade da mulher. Associado à disease (doença na perspectiva médica ou biológica), o estudo da illness (doença na perspectiva do doente e dos seus familiares e amigos) e da sickness (doença compreendida no seio das sociedades actuais) é fundamental para o bem-estar da paciente e o sucesso da terapia. Neste trabalho, propus-me investigar os comportamentos de doença em mulheres com cancro da mama no Instituto Português de Oncologia (IPO), em Coimbra, as suas redes de suporte familiar e social, bem como alertar a população para alguns problemas existentes no nosso sistema de saúde, apontando medidas que, futuramente, possibilitem uma resposta mais positiva das pacientes e a melhoria da sua qualidade de vida dentro e fora do hospital. O seguimento deste estudo nos IPO de Lisboa e do Porto será uma hipótese válida, com vista a uma maior uniformização dos cuidados de saúde prestados nas três instituições.

Palavras-chave Cancro da mama; etnografia; disease; illness; sickness.

Abstract Breast cancer is currently a serious public health problem, affecting one out of ten women throughout the life. In Portugal, there are approximately 4500 new occurrences every year and about 1500 are fatal. This disease has an enormous repercussion on the public space, mainly because it attacks a very symbolic organ in the woman's motherhood and femininity. Linked to disease (in the medical or biologic perspective), the study of illness (in the patient and his family and friends' perspective) and sickness (understood in the bosom of present societies) is essential for the well-being of the patient and the success of therapy. In this project, I proposed to do research into the sickness behaviour of women with breast cancer in IPO of Coimbra, their familiar and social support networks, as well as to alert the population to some problems of our health system, pointing out measures that 
in the future enable patients to have a more positive response and the improvement of their quality of life inside and outside the hospital. The following of this study at IPO of Lisboa and IPO of Porto will be a valid hypothesis, with a view to a bigger standardization of health care provided at the three institutions.

Keywords Breast cancer; ethnography; disease, illness, sickness.

\section{Preâmbulo}

O presente artigo decorre de um trabalho desenvolvido no âmbito da disciplina Dissertação de Mestrado em Antropologia Médica (Martins, 2010), sob a orientação do Professor Luís Quintais.

A intenção de realizar um trabalho deste tipo numa instituição de saúde coloca ao investigador, na maioria das vezes, obstáculos difíceis de ultrapassar, como por exemplo a morosidade do processo de obtenção de autorização para a realização do trabalho, já que o bem-estar e a confidencialidade dos pacientes têm de ser salvaguardados pelos órgãos dirigentes da instituição. A escrita de uma etnografia, um dos métodos de investigação mais poderosos da Antropologia, compreende uma dimensão intimista, na qual o etnógrafo interage, normalmente de um modo informal, com pessoas que conhece no espaço onde está a desenvolver o trabalho, e que naturalmente têm as suas próprias concepções da realidade. O seu desenrolar é imprevisível e a percepção do problema que o etnógrafo está a estudar vai-se alterando à medida que este contacta com diferentes pessoas, podendo ter repercussões surpreendentes no espaço social.

\section{Introdução}

O estudo dos mecanismos de doença no ser humano deve ser encarado sob uma perspectiva holística que integra três conceitos fundamentais, definidos em língua inglesa pelos termos disease, illness e sickness. Estes apresentam significados distintos: disease refere-se à doença num sentido estritamente biológico ou fisiológico, reflectindo-se, segundo o modelo biomédico, numa alteração do organismo ao nível estrutural e/ou funcional, e constituindo uma entidade objectiva que os profissionais de saúde, designadamente os médicos, procuram interpretar e solucionar através do saber e práticas médicas; illness reporta-se à experiência vivida pela pessoa 
na condição de doente, ao valor existencial e simbólico que atribui à sua doença, e ao modo como a própria, e os seus familiares e amigos compreendem, lidam, e respondem aos sintomas, incapacidades e sofrimento resultantes da mesma; por último, sickness define-se pela compreensão da doença no seio das populações e no que respeita à sua relação com as forças económicas, políticas e institucionais que influenciam as sociedades actuais (Kleinman, 1988).

No modelo biopsicossocial, que tem vindo a ganhar uma importância crescente, a disease é pensada como uma interacção simbólica entre factores orgânicos, psicológicos e sociais, que se manifesta e adquire um significado particular em cada paciente (Kleinman, 1988).

As doenças crónicas, devido principalmente ao seu grau de severidade e persistência ao longo de muitos anos, são um dos melhores exemplos em que, associado à disease, o estudo da illness e da sickness é absolutamente fundamental para o bem-estar do paciente e o sucesso da terapia. Na verdade, a sua trajectória pode contribuir intimamente para a concepção de vida e o desenvolvimento pessoal do sujeito, ao ponto da illness se tornar inseparável da sua história de vida (Kleinman, 1988).

Arthur Kleinman, médico psiquiatra e antropólogo norte-americano, é uma figura incontornável do estudo da illness e da sickness em pacientes crónicos. Segundo ele, uma das grandes lições que aprendeu durante os seus vinte anos de experiência clínica foi "que é possível falar com os pacientes, mesmo os mais angustiados, sobre a sua experiência actual de illness, e aquele testemunho e a ajuda para ordenar e situar aquela experiência podem ter um valor terapêutico" (Kleinman, 1988: xii). Kleinman defende que é vantajoso tanto para os clínicos como para o paciente aprender a interpretar a perspectiva deste e da sua família relativamente à illness, considerando mesmo que a interpretação das narrativas da illness é uma qualidade essencial no exercício da Medicina, embora esta seja pouco evidente na formação biomédica do mundo ocidental. Por outro lado, a experiência social está incorporada na forma como o paciente sente e experiencia os sintomas físicos, e no modo como se apresenta aos outros (Kleinman, 1988).

Uma consequência acidental da ultra-especialização e modernização progressivas dos sistemas de saúde, sobretudo nos países mais desenvolvidos, foi o direccionamento da atenção dos profissionais de saúde para a disease, remetendo a apreciação da experiência de illness vivida pelo paciente para segundo plano, o que constitui um dos aspectos mais antigos, poderosos e 
recompensadores da arte de curar (Kleinman, 1988). Os hospitais passaram de lugar de caridade a autênticos "templos da ciência" e têm crescido em dimensão e complexidade, devido não só ao aumento da procura dos cuidados hospitalares, mas também à enorme proliferação de serviços e especialidades médicas, fruto do desenvolvimento científico e tecnológico da medicina (Dias, 1999). Neste sentido, o conceito de "boa medicina" à luz do ideal da medicina científica é hoje em dia interpretado como sendo o rápido acesso ao hospital para tratamento da doença (Rosser e Maguire, 1982 in Dias, 1999). Ao longo da nossa demanda por tratamentos mais eficazes e melhores equipamentos hospitalares fomos perdendo a noção de que a saúde é mais influenciada pelas condições de vida das pessoas do que pelos cuidados médicos de que dispõem, e que a medicina, para além de uma disciplina científica, é também uma instituição social e cultural (Mechanic, 1988).

\section{Metodologia de trabalho}

Sendo a intersubjectividade o alicerce de um trabalho etnográfico, a componente prática deste baseou-se na recolha de testemunhos de mulheres com cancro da mama, quer sob a forma de um questionário, previamente aprovado pela Comissão de Ética do IPO de Coimbra, quer através de diálogos e observações ocasionais ao longo da sua estadia no hospital ou nas sessões de quimioterapia. No total foram entrevistadas 32 pacientes, 16 em regime de internamento e 16 em regime de ambulatório, no Serviço de Oncologia Médica, sem haver qualquer preferência por faixa etária e nível socioeconómico. Desta forma, pretendi realizar um estudo mais significativo que me permitiu extrapolar algumas conclusões para a generalidade das mulheres que sofrem de cancro da mama, assim como identificar factores de ordem social e económica que influenciam o seu percurso de vida. Tive também a oportunidade de falar com 9 profissionais de saúde do hospital, pertencentes às mais variadas áreas: 3 médicos especialistas em patologia mamária, 3 enfermeiros, 1 assistente social, 1 psicóloga e 1 psiquiatra. Tentei estabelecer um diálogo informal tanto com as pacientes como com os profissionais, não obedecendo a um sistema rígido de perguntas e abordando outros temas para além dos que constavam no questionário. Estive ainda presente, juntamente com uma assistente social, em duas reuniões de decisão terapêutica, onde as pacientes tomam conhecimento do diagnóstico 
e do plano terapêutico proposto pela equipa médica. Todos os dados foram recolhidos através de gravação áudio, quando permitido pelos inquiridos, e de anotações escritas num "diário de terreno", em que registei os acontecimentos que considerei mais relevantes em cada dia que estive no hospital, durante aproximadamente 4 meses.

Assim, consegui obter relatos na primeira pessoa a respeito da experiência com o cancro da mama, ou seja, da experiência de illness, bem como tirar conclusões quanto à categorização das pacientes como pessoa doente ou sick person, ambas condicionadas pelos seus contextos familiar, social e cultural. Para compreender melhor o conceito de sickness, achei pertinente contactar também com familiares e/ou amigos de algumas pacientes, única e exclusivamente com aqueles indicados por elas.

A recolha de dados não requereu a identificação dos titulares, sendo o anonimato de todos os participantes totalmente assegurado, através da atribuição de um nome fictício a cada uma das pacientes citadas no trabalho e da identificação de cada profissional pelo nome da sua profissão.

Por último, para além da revisão e pesquisa bibliográfica que fiz sobre o tema, assisti também a programas televisivos sobre o cancro da mama.

\section{A doença oncológica: o caso particular do cancro da mama}

Segundo a Organização Mundial de Saúde, o cancro é uma das principais causas de morte em todo o mundo (WHO, 2009). As doenças oncológicas representam actualmente a segunda causa de morte na maioria dos países ocidentais, incluindo Portugal, apenas ultrapassadas pelas doenças cardiovasculares (Esteves, 2007).

O cancro da mama está entre os cinco com maior taxa de mortalidade anual (WHO, 2009), sendo o mais frequente na mulher, e cuja taxa de incidência tem vindo a aumentar desde a segunda metade do século XX (Roche Portugal, 2008 b). Calcula-se que globalmente uma em cada dez mulheres irá desenvolver esta patologia ao longo da vida (Roche Portugal, 2008 b) e que esta conduza à morte de 519000 mulheres todos os anos (WHO, 2009). Em Portugal, são detectados aproximadamente 4500 novos casos por ano na população feminina, dos quais cerca de 1500 são mortais (Roche Portugal, 2008 c). Na população masculina a sua incidência ronda os $1 \%$, apresentando normalmente um prognóstico pior (Roche Portugal, 2008 c). 
Quando o cancro da mama é detectado e diagnosticado numa fase inicial, antes de se ter metastizado para outros tecidos do organismo, a sua taxa de sobrevivência pode atingir os $95 \%$ durante um período mínimo de 5 anos (Roche Portugal, 2008 b). O tratamento prescrito e o prognóstico variam de pessoa para pessoa e consoante o tipo de tumor (LPCC, 2008 a).

O seu desenvolvimento não pode atribuir-se a uma causa única. Conhecem-se alguns factores de risco, na sua maioria relacionados com os estilos de vida e as características reprodutivas próprias da vida moderna e ocidentalizada, tais como o tabagismo, o excesso de consumo de álcool, o excesso de gorduras na alimentação e o sedentarismo. Salienta-se que 5 a $10 \%$ dos casos diagnosticados apresentam características genéticas e hereditárias, que impõem um acompanhamento mais precoce e cuidadoso dos familiares da pessoa doente (LPCC, 2008 b). A maioria das mulheres com cancro da mama não tem história familiar da doença, verificando-se que, à excepção do envelhecimento, muitas delas não apresentam fortes factores de risco (Roche Portugal, 2008 d).

A vivência de uma doença oncológica ameaça a integridade física e psicológica da pessoa, tendo assim um impacto profundo na forma como esta se percepciona a si mesma e ao seu espaço social (Soares et al., 2000). O cancro da mama é uma das doenças com maior impacto no espaço público, não só pela sua alta incidência e associação a uma imagem de grande gravidade, mas também porque agride um órgão pleno de simbolismo na maternidade e na feminilidade da mulher (Roche Portugal, 2008 c). Tudo isto, aliado ao facto de ser o cancro mais comum na população feminina, levou à formação de lobbies e a uma extensa investigação na área clínica (Broom, 2001). Continuam-se a descobrir novos dados acerca das suas causas e novos modos de o prevenir, detectar e tratar. No futuro, as pessoas com cancro da mama podem esperar uma maior qualidade de vida e uma menor probabilidade de morrer devido à doença (Roche Portugal, 2008 c).

\section{IIIness: eu, a minha doença e os outros}

O caminho percorrido pelas mulheres com cancro da mama compreende, geralmente, quatro etapas principais: o diagnóstico, a cirurgia, os tratamentos e a reconstrução (esta última nem sempre possível). 


\section{O momento do diagnóstico}

Quando o cancro da mama é diagnosticado, a primeira reacção da mulher caracteriza-se muitas vezes pelo choque, embotamento ou incredulidade. Todavia, é comum desencadearem-se emoções mais intensas, tais como medo, ansiedade, depressão, raiva, pânico e sentimento de culpa (ainda que estejam muitas vezes dissimuladas sob uma aceitação e uma tranquilidade exteriores que as pacientes se esforçam por manter), havendo normalmente oscilações de humor (Ogden, 2004).

Patrícia, uma das pacientes da sala de quimioterapia, era auxiliar de acção educativa e tinha 47 anos. O cancro tinha-lhe sido diagnosticado há poucos meses: "Não acreditei, pronto, e foi de repente que também fiquei assim. Foi um choque, não estava à espera, nunca pensei que fosse maligno. Mas pronto...é para a frente."

Carolina, outra paciente que realizava quimioterapia, tinha 63 anos e estava reformada (anteriormente era farmacêutica). A doença também lhe tinha sido diagnosticada há pouco tempo: "Fiquei assustada ... realmente tocou-me bastante. Receosa das consequências do que é que poderia acontecer."

As consequências psicológicas que podem advir do diagnóstico e evolução de um cancro são inúmeras, afectando também os familiares e os amigos mais próximos dos pacientes. Ribeiro (1998) refere que tais consequências podem ser influenciadas por algumas variáveis como o tipo de cancro, as expectativas de sobrevivência do paciente, o grau de agressividade dos processos terapêuticos, as alterações na imagem corporal, os traços de personalidade, entre outras (Maia e Correia, 2008).

\section{Os tratamentos: cirurgia, quimioterapia e radioterapia}

As pacientes de cancro da mama têm ao seu dispor boas opções de tratamento. A doença pode ser tratada com recurso à cirurgia, quimioterapia, radioterapia, hormonoterapia e imunoterapia, podendo o médico optar por um ou pela combinação de dois ou mais tratamentos (Roche Portugal, 2008 b). Neste ponto destaco os tratamentos mais comuns e que melhor consegui estudar no hospital: a cirurgia, a quimioterapia e a radioterapia.

Muitas pacientes querem saber o máximo de informação sobre a doença e os métodos de tratamento disponíveis, assim como participar nas 
decisões relativas ao seu estado de saúde e aos cuidados médicos de que necessitam. Ter um maior conhecimento sobre a doença pode ajudá-las a colaborar com a equipa de profissionais e a reagir de forma mais positiva (Roche Portugal, 2008 d).

A cirurgia é o tratamento mais comum e o principal tratamento local. A quimioterapia e a radioterapia têm sido ao longo de muitos anos os principais tratamentos para o cancro da mama metastizado, travando a sua progressão através da acção de poderosos fármacos que destroem as células (citotóxicos) ou de radiação, respectivamente (Roche Portugal, 2008 b).

Quis saber junto dos profissionais quais os efeitos decorrentes da cirurgia e dos tratamentos de quimioterapia e de radioterapia que, em sua opinião, mais afectam o estado psicológico das pacientes.

"Da nossa parte a angústia é sempre maior para a quimioterapia, sobretudo por toda a imagem corporal que se altera, como o facto de cair o cabelo, e pela dependência dos outros no dia-a-dia." - Explica a assistente social. "A radioterapia é direccionada ao tumor. Só no caso de tumores cerebrais é que pode levar à queda do cabelo. Contudo, a zona da pele afectada pela radiação fica queimada, e se for uma zona com pêlos, então aí nunca mais crescem." Acrescenta que normalmente a mulher tem medo de se ver ao espelho, sendo a sua auto-imagem, feminilidade e vida sexual muito afectadas. "Elas têm receio que o marido lhes toque e não as aceite assim, tal como têm receio de se tocar a si mesmas."

A doutora de Psicologia diz-me que em termos de cirurgia é, sem dúvida, a perda da mama, uma situação com um impacto emocional tremendo, que mais afecta psicologicamente as mulheres. "De facto, para todos os efeitos, é uma mutilação, e portanto é muito difícil a pessoa adaptar-se àquela situação (na grande maioria dos casos é muito difícil) porque vai implicar, de algum modo, toda uma reformulação daquilo que é a nossa imagem corpo$\mathrm{ral}$, da forma como nos entendemos, da forma como olhamos no espelho e nos reconhecemos. Portanto, vai ser preciso um tempo de adaptação à nova realidade, e de facto é muito complicado. Para além disso, a cirurgia depois também deixa algumas dificuldades em termos da mobilidade do membro, ou dos dois eventualmente, e esse é também um processo muito dificil das pessoas aceitarem. Para além de terem perdido uma parte do seu corpo é sentirem que as tarefas que faziam anteriormente, agora não as podem fazer ou têm muita dificuldade." 


\section{Reconstruir: sim ou não?}

A maioria das mulheres considera os seios uma parte importante da sua feminilidade e identidade sexual. A hipótese de perderem um ou ambos aumenta a carga psicológica inerente a um diagnóstico deste tipo. Há mulheres que desejam conservar a mama a quase todo o custo, enquanto outras só se sentem completamente tranquilas se esta for removida. As mulheres que do ponto de vista emocional olham para a experiência da mastectomia como muito dolorosa podem pretender uma reconstrução mamária imediata ou a curto prazo, enquanto outras preferem não realizar mais cirurgias e optam por usar prótese no soutien (Ogden, 2004).

Anita, uma das pacientes do internamento que mais me marcou, tinha 52 anos e era assistente administrativa de um centro de saúde. A doença havia-lhe sido detectada há alguns meses num exame de rotina, no âmbito do programa de rastreio. Ainda não tinha feito cirurgia de reconstrução, mas pensava fazê-la mais tarde: "Sou muito vaidosa ... gosto muito de me sentir bem comigo, e agora sinto-me um trapo... Estou gorda, era mais elegante, e isto psicologicamente é que me afectou. Mas a doutora diz que depois da quimioterapia, lá para Outubro se tudo correr bem, podia fazer a reconstrução."

Mariana, outra das pacientes internadas cujo testemunho e imagem me ficaram mais presentes na memória, tinha 67 anos e desempenhava o cargo de funcionária administrativa na Segurança Social. Sabia do diagnóstico há 8 anos e, contrariamente à vontade de Anita, não pretendia fazer a reconstrução.

Abordo o mesmo assunto com a doutora de Psicologia: "Sobre essa questão temos, por exemplo, mulheres que aquando do diagnóstico ou quando é proposta a mastectomia pensam "Sim, claramente. Quando isto passar eu vou fazer a reconstrução, não há dúvida nenhuma sobre isso." Mas depois há alguns processos, dependendo dos tratamentos que fazem, em que não podem avançar logo para a reconstrução, têm de esperar algum tempo. E durante esse tempo adaptam-se muito bem à sua nova situação, o casal adapta-se muito bem, e portanto a reconstrução deixa de fazer sentido porque a pessoa sente-se bem, sente que está adaptada... Portanto, isto é sempre muito variável. (...) Que também se possa ajustar a ideia que as mulheres têm da reconstrução porque, pelo menos numa fase muito inicial quando começam a pensar nisso, é uma ideia muito idealizada da reconstrução, da recuperação do corpo tal como ele era. E isso é uma coisa que não acontece. Há pessoas que depois da reconstrução ficam muito, muito desiludidas com o resultado... 
e podem ser até resultados que do ponto de vista médico e da cirurgia estética ficaram óptimos, era o melhor que se podia fazer naquela situação. Mas de facto não é igual à outra mama. (...) O nosso trabalho também é muito isso, com muita informação e informação clara, para que as pessoas possam tomar uma decisão verdadeiramente informada."

\section{Eu e os outros}

O diagnóstico de cancro da mama pode trazer grandes mudanças para a vida destas mulheres e dos seus familiares, algumas difíceis de gerir. Para muitas a adaptação a toda a situação torna-se mais fácil se sentirem que recebem informação correcta e que têm à sua disposição bons serviços de apoio (Roche Portugal, 2008 a). Os familiares e os amigos podem ser uma fonte de apoio extremamente importante, mas eles também se deparam com as suas próprias dificuldades (Ogden, 2004). Embora uma situação desta natureza possa fortalecer as relações com os familiares e os amigos, pode igualmente desencadear stresse, estigma e evitamento em relação à pessoa doente (Maia e Correia, 2008).

Os profissionais de saúde também têm um papel essencial no modo como estas mulheres, normalmente tão vulneráveis do ponto de vista emocional, lidam com a sua condição física e psicológica (Ogden, 2004). No IPO de Coimbra, as pacientes com quem falei mostraram-se muito satisfeitas com o atendimento feito pelos profissionais.

"Realmente o nosso objectivo é que as pessoas se adaptem o melhor possivel às exigências da doença e dos tratamentos, que são exigências muito fortes, muito pesadas, e portanto temos que considerar qual é a hipótese que melhor nos ajuda." - Diz-me a doutora de Psicologia. "Nós geralmente temos aqui pessoas muito, muito diferentes. Por isso é que os colegas, principalmente os médicos, dizem que não tratam doenças, tratam pessoas. Porque se fossem doenças era tudo igual para toda a gente, não é? E não pode ser. De facto, nós vemos aqui como a parte psicológica, a parte emocional, faz muita diferença na adesão aos tratamentos, na forma como as pessoas encaram a doença de um modo mais optimista ou mais pessimista... (...) E, portanto, é também por isso que é importante que as equipas tenham profissionais com 
várias formações. (...) São olhares diferentes, de várias perspectivas, e daí resulta realmente aquilo que faz mais sentido para aquela pessoa."

"Eu acho que nós, sobretudo para termos empatia com os doentes e para podermos estabelecer um bom diálogo com eles, temos que ir ao encontro do doente." - Diz um dos médicos. "E para isso precisamos de ter uma visão abrangente da vida humana e das coisas, e portanto acho que mal de nós se só sabemos de Medicina. (...) A relação que se estabelece entre o médico e o doente é muito importante, podendo até ser terapêtica. Tenho que ter algum distanciamento, mas também não posso deixar de ser humano e sensivel a estas questões. Não são máquinas, são pessoas."

"O IPO está à frente ao nível de cuidar dos doentes, da humanização dos cuidados. Mais importante do que saber e ter uma boa técnica é o aspecto relacional entre as pessoas." - Acrescentou um dos enfermeiros.

Um movimento de suporte notável é conduzido pelas várias associações de apoio ao cancro da mama que existem actualmente, cuja ajuda psicológica e emocional disponibilizada às doentes tem sido determinante na promoção da sua qualidade de vida e na defesa dos direitos que lhes assistem. Voluntárias devidamente treinadas e que já tiveram cancro da mama visitam as pacientes nas enfermarias, dão-lhes informações e conselhos úteis, e prestam-lhes apoio emocional. Muitas vezes há a partilha das suas experiências com a doença, o tratamento, a reabilitação e a reconstrução mamária.

Neste capítulo, reflicto ainda sobre outros aspectos relevantes para se compreender toda a dimensão do cancro da mama, intercalando mais alguns testemunhos.

O impacto psicossocial do cancro da mama depende muito da idade que a mulher tem no momento em que lhe é transmitido o diagnóstico. Isto é, desde logo, perceptível na forma como encaram a doença e como me falam acerca dela.

Margarida estava no internamento há quase uma semana devido a ter reagido mal a um ciclo de quimioterapia, tinha 44 anos e era professora. Soube que sofria de cancro da mama aos 30 anos de idade. "Achei que os meus filhos eram muito pequeninos e que iam ficar sem mim de um momento para o outro." - Disse-me emocionada. "Eu não lhes quis estragar a infância nem a adolescência e fui-lhes escondendo a maior parte das coisas. Eles sabem que a mãe 
não tem uma saúde muito boa, mas como são muito espertos perguntam pouco e observam muito, e como me vêem sempre bem disposta não perguntam nada."

Érica, uma gerente comercial de 48 anos que estava na sala de quimioterapia, contou-me que ficou em pânico ao saber o diagnóstico: "Tenho um filho com 8 anos... Medo da morte. Não é medo da morte, o cancro da mama já tem cura, mas a minha melhor amiga há 2 anos morreu devido a um cancro da mama... (...) Éramos muito amigas, era a minha melhor amiga, e ela tinha uma menina com 8 anos. E o que é que eu pensei? Pensei nela e na situação dela. O meu medo não é o cancro da mama, que a gente tira a mama (quer é viver), a gente pensa mais é nos filhos, com 8 anos é pequenino. Mas depois pensei "Não é isto que me vai matar. E vou lutar."

Calcula-se que cerca de $25 \%$ dos casos de cancro da mama ocorram em mulheres com menos de 50 anos, porém ainda pouco se sabe sobre as consequências da doença em mulheres jovens e o impacto ao nível familiar. Estudos que incluíram um grupo de mulheres jovens demonstraram que estas experimentam níveis elevados de ansiedade e stresse devido ao diagnóstico, comparativamente a um grupo de mulheres mais velhas. Efectivamente, a vida das mulheres em idade activa envolve o desempenho de múltiplos papéis sociais, designadamente ser mãe de filhos pequenos, ser esposa e dona de casa, e ter um emprego (Coyne e Borbasi, 2006).

Em geral, as mulheres que tiveram cancro da mama podem engravidar e a gravidez em si não altera o risco de voltar a desenvolver a doença. No entanto, pode ser complicado planear a melhor altura para isso acontecer e a mulher pode ter de fazer opções quando os tratamentos se prolongam por alguns anos. A doença também induz alterações na sua fertilidade, e a ausência de menstruação e a menopausa precoce podem resultar dos tratamentos que ajudam a combatê-la. Para muitas destas mulheres a maternidade é uma fase importante após o terminar dos tratamentos (Jovem com Cancro da Mama, 2009).

Outro problema que as pacientes enfrentam frequentemente após a cirurgia é a mudança na forma como encaram o corpo e como isso se reflecte nos seus sentimentos e actividades sexuais (Ogden, 2004).

"A sexualidade é um pouco esquecida. Às vezes perguntam-nos a nós, pois têm vergonha ou receio de falar com o médico. Nós somos um todo, e portanto a sexualidade não pode ser deixada de lado." - Alerta a doutora do Serviço Social. 
Broom nota ainda que pouco se fala sobre a perda de um local de prazer sexual para a mulher (Broom, 2001).

Por outro lado, a atitude do parceiro é fundamental, devendo este esforçar-se por manter uma relação de proximidade e de cumplicidade, inteirar-se sobre todo o processo clínico e ajudar a mulher na sua recuperação (Jovem com Cancro da Mama, 2009).

Quanto ao diagnóstico de recorrência, segundo os médicos, ainda é mais traumatizante para as pacientes do que o diagnóstico inicial. "As doentes sofrem muito mais quando lhes transmitimos que a doença veio para trás e que têm metástases. Sem dúvida, ai tem um impacto brutal. Porque se até aí a doente esteve na perspectiva de que fez tratamentos e vai ficar bem, quando a doença volta para trás, como nós explicamos aos doentes, nunca mais há perspectiva de cura... há perspectiva de tentarmos controlar a doença. Mas temos que a encarar como uma doença crónica, nunca mais a vamos curar." - Diz-me uma médica.

A morte, o último aspecto que quero focar, é uma palavra ainda muito associada ao diagnóstico de doença oncológica. A maioria das pessoas não enfrenta verdadeiramente o facto de que um dia irá morrer. Porém, $o$ diagnóstico de cancro mostra-lhes nitidamente que tal irá acontecer e que poderá ser mais cedo do que esperavam, o que provoca um grande impacto emocional, um sentimento de incerteza relativamente ao futuro e de perda de controlo sobre a própria vida (Ogden, 2004). Esta é uma das questões mais complicadas de abordar com as pacientes, os familiares, os amigos e mesmo os profissionais de saúde.

"Eu não penso muito se as pessoas vão viver ou se vão morrer, pelo menos a mim não me ajuda." - Diz-me a doutora de Psicologia. "Sinto que isso são coisas que nos ultrapassam na maioria da proporção. Portanto, essencialmente a decisão em que eu sinto que posso fazer a diferença e que as pessoas podem fazer a diferença é como é que vão viver cada dia, não é quantos dias vão viver. E nesse sentido, as pessoas que vivem com mais esperança e com mais optimismo fazem diferença do ponto de vista da adesão aos tratamentos; da relação com a equipa aqui; em casa a familia vive melhor; quando há filhos pequenos eles tendem a desenvolver menos problemas de comportamento; e isso é que é qualidade de vida e isso é que é bem-estar, independentemente do tempo que a pessoa tenha." 


\section{Sickness: o papel do doente oncológico na sociedade}

O doente deve ser a figura principal nos processos e relações sociais envolvidos no acto terapêutico. As suas dimensões psicossociais são, no geral, invisíveis para os profissionais de saúde no contexto hospitalar. Os hospitais são organizações profissionais que nalguns aspectos se constituem como um mundo próprio, com múltiplas configurações desconhecidas para a maioria dos utentes (Dias, 1999).

O cancro da mama tem vindo a assumir-se cada vez mais como uma doença crónica, o que configura a informação que é prestada às pacientes como uma das estratégias mais poderosas, passível de contribuir para a mudança da representação social do doente, de mero caso clínico à condição de ser psicossocial (Dias, 1999). Perguntei então às pacientes e aos profissionais como são vistas, na sua opinião, as mulheres com cancro da mama na nossa sociedade e cultura.

Na opinião de Anita, estas mulheres são vistas com pena, pois era assim que ela antes olhava para elas: "Quando via as pessoas com lenço era o que mais me atormentava, ficava muito sensibilizada (...) nunca pensando eu que iria passar pelo mesmo."

Carolina mostrou-se um pouco hesitante: "Acho que hoje em dia as pessoas encaram melhor do que antigamente, embora ainda haja muitos casais que tenho conhecimento que se separam precisamente porque a mulher teve este problema não é? Mas também acho que os maridos ajudam... e hoje em dia as pessoas já têm as próteses e têm isto e aquilo, apesar de eu tentar permanecer com o aspecto que tinha. (...) Aconteceu-me foi uma vez que estive com um grupo de senhoras que eu costumo estar... Eu fiquei chocada por ver que elas estavam chocadas quando me viram porque não sabiam como é que haviam de lidar comigo. Eu é que depois me comecei a rir para elas e comecei "Então, está tudo bem?" Mas vê, as pessoas ficaram quase mudas e olhavam para mim, parece um tabu, não sabem como é que hão-de lidar com a pessoa."

Margarida disse-me que nunca foi marginalizada nem sentiu pena em relação a si por parte das outras pessoas: "Antes pelo contrário. Sim, já há muitos apoios e as pessoas dizem "Ah que grande mulher, que passou por isto e passou por aquilo." 
Érica contou-me que no meio onde trabalha não teve muito apoio da entidade patronal: "Não me ligaram nenhuma. E depois quando andamos com os lenços é aquela "coitadinha", "Ah tão nova, coitadinha." Contudo, não tem sentido nenhum a reacção negativa por parte dos outros: "Não, não, até pelo contrário. Aqueles amigos antigos, de juventude, voltaram todos assim que souberam. Em questão de apoio tenho muito apoio e acho que isso é fundamental. E depois é ter um filhote com 8 anos, que a gente olha para aquilo e dá-nos força. Eu sei que há muita gente na minha situação que não tem apoio nenhum."

"Há muitas mulheres que passam perfeitamente despercebidas no meio da população e que nunca se manifestam, nem tão-pouco dão a entender que são realmente portadoras de cancro da mama. Há outras que, pelo contrário, se tornam umas "coitadinhas" porque foram operadas e já não podem fazer mais nada, e muitas vezes sem razão. Há outras que infelizmente têm realmente a doença avançada, que são obviamente vítimas da própria doença, e que têm um transtorno da sua vida diária. No entanto, presentemente podemos realçar por exemplo o papel que as telenovelas têm tido, o papel que as pessoas públicas têm tido nas revistas (que merecem sempre alguma atenção da população em geral) e as que têm dado a cara quando portadoras de cancro da mama, com sobrevivências boas e com qualidade de vida. Isso é um estímulo para as restantes mulheres e acho que tem sido também bastante importante e que realmente é muito bom que se continue a dar esta imagem." - Diz-me outra médica.

Segundo Sontag (1978), o modo como falamos de uma doença e escrevemos sobre ela, e em particular as metáforas que utilizamos, irão ter um impacto palpável na vivência dessa condição. Para este processo contribuem não só os próprios doentes, mas também os médicos, os investigadores, os governantes, e os fabricantes e publicitários de medicamentos e outros tratamentos. No entanto, Dorothy Broom, investigadora australiana que realizou um estudo sobre o cancro da mama, afirma que a linguagem e as metáforas utilizadas para se falar acerca de uma doença nunca são suficientes para abarcar a experiência corpórea de quem passa pela mesma (Broom, 2001).

Um estudo pioneiro realizado em Portugal no ano de 2007 revela que a espiritualidade pode influenciar a qualidade de vida dos doentes oncológicos que estão a fazer quimioterapia. Constatou-se que quanto mais elevados eram os índices de espiritualidade do doente, maior era a sua qualidade de 
vida, nomeadamente ao nível do bem-estar físico, funcional e emocional, conclusões suportadas por estudos internacionais já publicados. "Hoje começamos a compreender que não é possivel tratar a doença isoladamente sem considerar o meio sociocultural que envolve o paciente, as suas emoções e cognições pessoais sobre a saúde e a doença, existindo um grande esforço por parte de alguns técnicos de saúde no sentido de fazerem com que o doente se sinta parte integrante do tratamento, contribuindo assim de forma activa para a sua cura." - Afirma João Pestana, psicólogo responsável pela investigação. Ainda de acordo com o estudo, os custos económicos, sociais, familiares e culturais com o cancro não são conhecidos, facto que vem dificultar muito o combate à doença ao nível do tratamento e da prevenção, impedindo que sejam delineadas estratégias de intervenção mais eficazes. "Terem fé, sentirem-se completas e em paz consigo mesmas e com os outros" pode ser fundamental em situações de maior gravidade (Esteves, 2007).

\section{Conclusão}

Os principais objectivos deste trabalho foram cumpridos. O primeiro objectivo era investigar os comportamentos de doença em pacientes com cancro da mama, ou seja, a relação entre a percepção de estar doente e a sua expressão corporal e verbal. Ao longo das conversas que mantive fui-me apercebendo que, apesar de todas as pacientes terem a sua própria personalidade e diferentes maneiras de reagir à doença e às mudanças na sua vida, ao passarem pelas mesmas etapas ao longo do seu trajecto clínico vão apresentar alguns comportamentos semelhantes.

O segundo objectivo era investigar as redes de suporte familiar e social às quais as pacientes recorrem ou de que dispõem, bem como quais os comportamentos de doença que geram apoios por parte dos outros e da sociedade em geral. Constatei que muitas mulheres preferiam manter o conhecimento da sua doença no seio familiar mais próximo, não só para evitarem rumores e olhares por parte dos outros, mas, também, para não terem de responder constantemente às perguntas relativas ao seu estado de saúde, principalmente as mulheres mais jovens e com filhos pequenos. $\mathrm{O}$ apoio dos familiares e dos amigos é absolutamente fundamental, pois o peso psicológico e emocional da vivência de uma doença oncológica, para já não referir as limitações físicas que provoca, é demasiado grande para o suportarem sozinhas. No seu lar, a manutenção de uma relação de proximidade 
e de intimidade com o marido ou companheiro é muito importante e pode influenciar significativamente a forma como a mulher reage à alteração da sua auto-imagem e age no seu meio social. Por outro lado, as associações de apoio ao cancro da mama disponibilizam apoio psicológico às pacientes e aos seus familiares, seja através de consultas individuais com um psicólogo ou em sessões de terapia de grupo, onde diferentes mulheres partilham umas com as outras o seu dia-a-dia, as suas dúvidas, os seus receios, os seus desejos e as estratégias que têm utilizado para lidar melhor com a doença. Algumas destas associações, tais como a Liga Portuguesa Contra o Cancro (LPCC) e a Laço, ajudam também na aquisição de próteses mamárias e capilares, e de equipamento hospitalar, para além de se assumirem como uma via essencial de divulgação da doença e de implementação de rastreios ao nível nacional. Outro movimento de apoio que tem vindo a crescer nos últimos anos é os blogues da internet, onde as participantes partilham igualmente o seu quotidiano e a sua experiência com a doença, trocam conselhos e combinam encontros. Assinalo ainda que na generalidade dos hospitais existe um conjunto de profissionais do Serviço Social, da Psiquiatria e da Psicologia prontos para esclarecer quaisquer dúvidas e ajudar as pacientes no que for necessário. A sociedade em geral é bastante receptiva em ajudar estas mulheres e contribuir nas campanhas e nos peditórios organizados a favor da doença, sendo do conhecimento da maioria que o cancro da mama pode surgir em qualquer mulher e, se não for detectado e tratado atempadamente, pode mesmo levar à morte. As mulheres com quem contactei não aparentaram comportar-se intencionalmente de forma a chamar a atenção das outras pessoas para o seu problema de saúde, mas diziam-me que as pessoas suas conhecidas ao saberem que alguém sofre de cancro e que o seu quadro clínico é grave, procuram sempre ajudar dentro do possível, sendo uma doença com uma representação social negativa ainda muito marcada na nossa sociedade.

O terceiro e último objectivo era apontar algumas direcções de intervenção que, no futuro, permitam uma resposta mais positiva das pacientes ao cancro da mama, bem como a melhoria da sua qualidade de vida dentro e fora do meio hospitalar. De seguida, passarei a expor cada um dos tópicos mencionados pelas pacientes, seus familiares e amigos, e os profissionais participantes neste trabalho, procurando estabelecer conexões entre si.

Em primeiro lugar, o transporte das pacientes entre o seu local de residência e os hospitais dos grandes centros urbanos. Normalmente as 
pacientes vão de ambulância ou de táxi até ao hospital com outras pessoas que moram na mesma zona. Contudo, muitas vezes o transporte chega atrasado ao hospital e as pacientes têm consultas e tratamentos aos quais não podem faltar ou, por outro lado, se uma determinada consulta se atrasa algumas horas, as pacientes arriscam a que a sua ambulância ou táxi se tenha de ir embora, tendo elas de regressar a casa pelos seus próprios meios e pagar a deslocação do seu bolso. Para além disto, nem todos os médicos de família dos centros de saúde aceitam passar credenciais para o transporte das pacientes até ao hospital, o que leva a que algumas coloquem a hipótese de não irem às consultas por não poderem pagar a deslocação, sobretudo as que moram mais longe. Portanto, é necessário fazer-se uma avaliação rigorosa de quem deve ter direito à credencial e em que situações, sendo abrangidos os casos em que as consultas ou os tratamentos não se realizam à hora marcada, uma vez que as pacientes são alheias a essa situação e não têm de ser prejudicadas. Ainda neste campo, importa referir que a articulação entre os centros de saúde e os hospitais centrais tem de ser melhorada, já que alguns centros reencaminham imediatamente os doentes oncológicos para os IPO sem se justificar, havendo deslocações e gastos desnecessários.

Deve existir um acompanhamento psicológico continuado dentro e fora do hospital, o qual deve iniciar-se nas primeiras consultas, de modo a que o choque no momento do diagnóstico seja menor, e manter-se após a paciente ter alta hospitalar, até à sua recuperação total. De facto, algumas mulheres confessaram sentir-se um pouco desamparadas e sozinhas ao irem para casa sem um apoio psicológico regular. Torna-se assim necessário e premente que os hospitais contratem um maior número de psicólogos, psiquiatras e assistentes sociais, o que certamente irá diminuir algumas das carências que existem actualmente, e lhes proporcionem boas condições para eles poderem desenvolver o seu trabalho. Uma consulta de psicologia ou de psiquiatria deve ser encarada como mais uma etapa no processo de tratamento da doente, pelo que também nestes casos o transporte deve ser comparticipado pelo Estado, sob pena de as pessoas faltarem às consultas, o que poderá agravar o seu quadro clínico.

Todas as pacientes referiram que a comparticipação da LPCC nas próteses mamárias e capilares é um factor muito positivo, já que muitas não conseguiriam pagar o seu valor na totalidade. No entanto, queixam-se que o reembolso demora muito tempo e que inicialmente a quantia que têm de pagar continua a ser demasiado elevada para as pessoas com menos recursos económicos. 
A reconstrução mamária é, segundo os profissionais, um dos aspectos em que a abordagem às pacientes de cancro da mama no IPO de Coimbra falha. Devido ao facto de não existir nenhum cirurgião plástico na casa (apesar de existirem protocolos a decorrer nesse sentido) e de haver sempre pessoas com tumores que precisam de ser removidos, não há muito tempo e espaço em termos de bloco operatório para a realização destas cirurgias, que são englobadas no grupo das cirurgias estéticas e normalmente requerem mais de uma intervenção para serem concluídas. Cabe então aos dirigentes hospitalares decidirem em que hospitais deve existir esta cirurgia e assegurar que as pacientes sejam atendidas num curto espaço de tempo, uma vez que a reconstrução pode ser um factor decisivo para a recuperação total de muitas mulheres. Foi igualmente referido que devia haver mais informação disponível sobre o processo de reconstrução mamária, de modo a que as mulheres tomem uma decisão informada.

$\mathrm{O}$ regime de baixas no emprego deve ser revisto. Muitas pacientes queixam-se das dificuldades que a diminuição do seu rendimento mensal, durante o período em que não podem trabalhar, acarreta, sobretudo quando se tratam de casais jovens em início de vida e com filhos pequenos. A maioria diz que há falta de apoio e incompreensão por parte da entidade patronal, que as faz sentir menos válidas e incapazes de desempenhar as suas funções. Uma alternativa para manterem os seus postos de trabalho, em vez de serem dispensadas ou reformadas é, por exemplo, a reorganização da sua função dentro de uma determinada empresa. $\mathrm{O}$ facto de poderem continuar a trabalhar e a contribuir para a empresa ajuda-as no processo de recuperação e muitas preferem manter-se activas enquanto os tratamentos o permitem.

$\mathrm{Na}$ oncologia a abordagem multidisciplinar é incontestável porque o cancro encerra em si muitos aspectos para além dos estritamente médicos, e que são igualmente importantes para a recuperação do doente. No que respeita ao cancro da mama, impõem-se novos desafios aos profissionais, uma vez que o perfil e a idade das pacientes têm vindo a alterar-se nos últimos anos. Actualmente observa-se que cada vez mais são afectadas mulheres jovens, o que levanta questões como a fertilidade e a maternidade, que devem ser seriamente debatidas por políticos e profissionais da área da oncologia. Um dos aspectos que deve ser alvo de reflexão é o impacto que uma notícia deste género provoca nos filhos, apesar de muitas mulheres lhes esconderem a doença durante vários anos. Os profissionais de saúde devem procurar actualizar os seus conhecimentos, de forma a estarem mais 
preparados para lidar com este grupo etário. Segundo a psicóloga, deveria existir um aconselhamento para estas mães, o que pode inclusive permitir que se detectem perturbações comportamentais nas crianças.

Fui ainda alertada pelos médicos para a ausência de supervisionamento e de regulamentação rigorosos nos hospitais e clínicas privadas, onde muitas vezes falta essa abordagem multidisciplinar no tratamento da doença oncológica. Para os profissionais, o Sistema Nacional de Saúde Português tem vindo a destacar-se como um dos melhores no mundo inteiro e a sua universalidade nunca pode ser colocada em causa.

Para terminar, gostaria de realçar que o Estado deve mobilizar mais apoios económicos para os hospitais e as universidades públicos, permitindo que haja mais investigação na área do cancro, e mais especificamente do cancro da mama, facilitando o acesso das pacientes aos novos fármacos desenvolvidos com eficácia e com resultados positivos no tratamento da doença.

Atendendo a estas e às demais questões expostas ao longo do trabalho, é importante haver mais financiamento para estudos sobre a outra "face", a "face humana", da doença oncológica, pois o cancro não existe fora de um sujeito com uma história de vida particular, com uma personalidade própria e que tem pensamentos e sentimentos em relação ao mundo onde vive.

Uma sugestão que aqui deixo para o seguimento deste trabalho no futuro será conduzir um estudo semelhante nos IPO de Lisboa e do Porto, comparando-se posteriormente os resultados obtidos com os do presente estudo, de forma a se detectarem as maiores discrepâncias entre os três hospitais e consequentemente poderem adoptar-se planos estratégicos para proceder à sua uniformização.

\section{Referências bibliográficas}

Broom, D. 2001. Reading breast cancer: reflections on a dangerous intersection. Health, 5(2): 249-268.

Coyne, E.; Borbasi, S. 2006. Holding it all together: breast cancer and its impact on life for younger women. Contemporary Nurse, 23(2): 157-169.

Dias, M. R. 1999. A doente veterana: saberes esquecidos nos sistemas de saúde. Análise Psicológica, 3(17): 499-512. 
Esteves, V. 2007. Espiritualidade influencia qualidade de vida do doente oncológico. Semanário, 26 de Outubro: 19.

Jovem com Cancro da Mama. 2009. [online]. Lisboa, Liga Portuguesa contra o Cancro. [Consultado em 9-7-2009] Disponível em: http://www.jovemcomcancrodamama.com.

Kleinman, A. 1988. The illness narratives: suffering, healing \& the human condition. New York, Basic Books, Inc.

Liga Portuguesa Contra o Cancro. 2008a. Tipos de cancro: escolha do tratamento. [online]. Lisboa, Liga Portuguesa Contra o Cancro. [Consultado em 16-092008]. Disponível em: http://www.ligacontracancro.pt/gca/index.php?id=185.

Liga Portuguesa Contra o Cancro. 2008b. Tipos de cancro: factores de risco. [online]. Lisboa, Liga Portuguesa Contra o Cancro. [Consultado em 16-092008]. Disponível em: http://www.ligacontracancro.pt/gca/index.php?id=179.

Maia, L.; Correia, C. 2008. Consequências psicológicas, estratégias de coping e intervenção na doença oncológica: uma revisão da literatura para aplicação prática. [online]. Psicologia.com.pt - O Portal dos Psicólogos. [Publicado em 11-9-2008]. Disponível em: http://www.psicologia.com.pt/artigos/textos/ A0445.pdf.

Martins, D. I. S. 2010. Uma etnografia sobre mulheres com cancro da mama. Tese de Mestrado em Antropologia Médica. Departamento de Ciências da Vida, Faculdade de Ciências e Tecnologia, Universidade de Coimbra.

Mechanic, D. 1988. Book Reviews: "Medicine and culture: varieties of treatment in the United States, England, West Germany and France" by Lynn Payer (New York: Henry Holt and Co., 1988) and "The illness narratives: suffering, healing and the human condition" by Arthur Kleinman (New York: Basic Books, 1988). Health Affairs, 7(5): 169-172.

Ogden, J. 2004. Compreender o cancro da mama. Lisboa, Climepsi Editores.

Roche Portugal. 2008a. Cancro da mama HER2+. [online]. Amadora, Roche Farmacêutica Química. [Consultado em 20-8-2008]. Disponível em: http://www. roche.pt/sites-tematicos/her2.

Roche Portugal. 2008b. O cancro da mama. [online]. Amadora, Roche Farmacêutica Química. [Consultado em 20-8-2008]. Disponível em: http://www.roche.pt/ sites-tematicos/infocancro/index.cfm/tipos/cancro-da-mama.

Roche Portugal. 2008c. Cancro da mama: quem está em risco. [online]. Amadora, Roche Farmacêutica Química. [Consultado em 20-8-2008]. Disponível em: http://www.roche.pt/sites-tematicos/infocancro/index.cfm/tipos/cancro-damama/cdm-sinais-de-alerta. 
Roche Portugal. 2008d. O tratamento do cancro da mama. [online]. Amadora, Roche Farmacêutica Química. [Consultado em 20-8-2008]. Disponível em: http://www.roche.pt/sites-tematicos/infocancro/index.cfm/tipos/cancro-damama/cdm-tratamento.

Soares, M. A.; Moura, M. J.; Carvalho, M.; Baptista, A. 2000. Ajustamento emocional, afectividade e estratégias de coping na doença do foro oncológico. Psicologia, Saúde e Doenças, 1(1): 19-25.

World Health Organization. 2009. Cancer: fact sheet n. 297. [online]. Geneva: World Health Organization. [Accessed 14-7-2009]. Available at: http://www. who.int/mediacentre/factsheets/fs297/en/index.html.

Artigo recebido a 16 de Dezembro de 2009 e aceite a 13 de Julho de 2010. 